Rev. Elet. em Gestão, Educação e Tecnologia Ambiental (e-ISSN: 2236-1170)

\title{
PREFERÊNCIAS DO CONSUMIDOR DE ÓLEO DIESEL EM FAXINAL DO SOTURNO-RS
}

\section{CONSUMER PREFERENCES OF DIESEL IN THE FAXINAL SOTURNO-RS}

\author{
Dione Somavilla Marzari ${ }^{1}$, Andréa Cristina Dorr ${ }^{2}$, Jaqueline Carla Guse ${ }^{3}$, Marivane Vestena \\ Rossato $^{4}$ \\ ${ }^{1}$ Universidade Federal de Santa Maria (UFSM) - Bacharel em Ciências Econômicas. E-mail: \\ dionemarzari@hotmail.com; \\ ${ }^{2}$ UFSM - Profa. Adjunta do Departamento de Ciências Econômicas. E-mail: andreadoerr@yahoo.com.br; \\ ${ }^{3}$ UFSM - Aluna do curso de Ciências Contábeis. E-mail: drjaquelinecarla@yahoo.com.br; \\ 4UFSM - Profa Adjunta do Departamento de Ciências Contábeis. E-mail: marivavest@gmail.com
}

\section{http://dx.doi.org/10.5902/223611708779}

\section{RESUMO}

O Brasil ocupa posição de destaque no consumo de óleo diesel e tornou-se auto-suficiente na produção de petróleo a partir de 2006. Diversos trabalhos envolvendo o comportamento do consumidor de óleo diesel já foram realizados no país. No entanto, nenhum estudo desta natureza foi realizado em Faxinal do Soturno/RS e região. O objetivo deste estudo é identificar o padrão comportamental de consumo do consumidor de óleo diesel em Faxinal do Soturno/RS. Os dados utilizados para análise são de natureza primária, obtidos através da aplicação de formulários estruturados diretamente aos consumidores de óleo diesel no município. Os resultados mostram que o óleo diesel mais utilizado pelo consumidor é o S1800 e o S50, de modo que o S500 é o menos consumido. Conclui-se que fatores como preço e recomendações da fabrica são os principais atributos avaliados pelos entrevistados na sua escolha.

Palavras-chave: consumo de combustíveis, óleo diesel, meio ambiente, preço.

\begin{abstract}
Brazil occupies a prominent position in diesel consumption, and became self-sufficient in oil production from 2006. Several studies involving consumer behavior of diesel have been performed in the country. However, no study of this kind was held in the Faxinal Soturno/RS and region. The objective of this study is to identify the behavioral patterns of consumer consumption of diesel in the Faxinal Soturno / RS. The data used for analysis are of primary nature, obtained by applying structured forms directly to consumers of diesel in the city. The results show that the use of three types of diesel (S1800, S500 and S50) presents itself on average 300 liters per month. Diesel fuel is most commonly used by the consumer S1800 and S50, so that the S500 is less consumed. We conclude that factors such as price and recommendations of the manufactures are the key attributes valued by the interviewees in their choice.
\end{abstract}

Keywords: fuel consumption, diesel, environment, price 


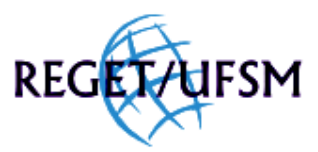

MARZARI et all , v(11), no 11, p. 2377-2388, JUN, 2013.

Rev. Elet. em Gestão, Educação e Tecnologia Ambiental (e-ISSN: 2236-1170)

\section{INTRODUÇÃO}

O Brasil é um país historicamente dependente de óleo diesel e desde 2006 tornou-se um país auto-suficiente na produção de petróleo. Segundo a Agência Nacional de Petróleo, Gás Natural e Biocombustível (ANP, 2012), o consumo de diesel pode ser dividido em três grandes setores: o de transportes, representado por $75 \%$ do total consumido; o agropecuário, representado por $16 \%$ do consumo e o de transformação que utiliza cerca de $5 \%$ do consumo total do diesel. O óleo diesel é o produto oleoso mais abundante obtido a partir da refina do petróleo. Sua composição apresenta basicamente hidrocarbonetos (compostos orgânicos que constituem átomos de carbono e hidrogênio) e em baixas concentrações de enxofre, nitrogênio e oxigênio. É um produto inflamável, com nível médio de toxicidade, pouco volátil, sem matéria em suspensão, límpido com cheiro forte e característico (ANP, 2012).

Segundo dados da refinaria Alberto Pasqualini (REFAP, 2012) em Canoas/RS e a refinaria Ipiranga em Rio Grande/RS, as mesmas responsáveis por todo o refino do petróleo que chega ao estado, ambas refinaram 121.337 barris de petróleo por dia durante o ano de 2011, o que representa cerca de $6,94 \%$ do total nacional. Os dados também mostram que o principal produto derivado é o óleo diesel.

Além da produção, as vendas de óleo diesel superaram o crescimento do PIB, encerrando em 2011 com aumento de 6,8\% no volume e respondendo por quase 50\% da matriz veicular brasileira. De acordo com o relatório de FECOMBUSTIVEIS (2012), as vendas de óleo diesel garantiram para o setor público, um montante de R\$ 29,4 bilhões em arrecadação em 2010.

Segundo o Sindicato Nacional das Empresas Distribuidoras de Combustíveis e Lubrificantes (SINDICOM, 2012), o diesel, combustível mais utilizado no país, teve um aumento de vendas em $6,8 \%$, totalizando 55,8 bilhões de litros no ano de 2012. Em 2012, o diesel foi marcado pela chegada do S50, que é o óleo diesel com menor teor de enxofre no mercado, recomendado para veículos com motor a partir do ano de 2012, devido às suas características o mesmo melhora a partida a frio. Este óleo diminui a formação de depósitos no motor e reduz em até $90 \%$ a emissão de enxofre e a fumaça branca.

Esse diesel foi uma opção para diminuir os problemas do óleo diesel brasileiro, que possui diversos problemas. Entre eles está o alto teor de enxofre, a degrabilidade e adulteração do óleo diesel. Devido ao alto teor de enxofre no combustível brasileiro houve grandes gastos com a saúde pública (CNT, 2012). De acordo com a resolução no 403 de 11 de novembro de 2008 do Conselho Nacional de Meio Ambiente (CONAMA), ficou estabelecido os novos limites máximos de emissão de poluentes de diesel em veículos automotores novos e importados.

Neste contexto, tem-se a necessidade de avaliar o comportamento do consumidor de óleo diesel, uma vez que, nos últimos tempos, além do aumento do consumo houve também um aumento de preços, sendo este proporcionado pelo elevado número de vendas de carros novos que utilizam diesel S50. (SINDISCOM, 2012).

Segundo Silva (2009), entender o comportamento do consumidor abre diversas portas para compreender suas decisões de consumo, além de auxiliar os profissionais do setor na preparação das estratégias para o desenvolvimento de suas atividades.

Diversas pesquisas envolvendo a escolha do consumidor sobre óleo diesel já foram realizados no país. No entanto, nenhum estudo desta natureza foi realizado em Faxinal do 


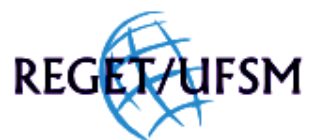

MARZARI et all , v(11), no 11, p. 2377-2388, JUN, 2013.

Rev. Elet. em Gestão, Educação e Tecnologia Ambiental (e-ISSN: 2236-1170)

Soturno/RS e região. Devido ao fato dos consumidores apresentarem diferentes comportamentos de uma localização geográfica para outra, estudar as características de consumo local se torna um problema de pesquisa de valor para compreender quais são as exigências e preferências dos consumidores por produtos e quais características específicas são buscadas por eles. Portanto, o objetivo deste estudo é identificar o padrão comportamental de consumo do consumidor de óleo diesel de Faxinal do Soturno - RS.

\section{METODOLOGIA}

Para a realização do trabalho, utilizou-se de uma pesquisa de natureza aplicada, visando buscar elementos que caracterizam o comportamento do consumidor de óleo diesel na cidade de Faxinal do Soturno/RS. Assim, o método de procedimento adotado neste estudo é o estatístico, que fornecerá informações quantificáveis e qualificáveis para a análise do comportamento do consumidor.

Conforme Gil (1995), o método estatístico tem grande importância na investigação de cunho social, fundamentando-se na aplicação da teoria da probabilidade. Isso significa que os resultados apresentam razoável grau de precisão e têm grande possibilidade de serem verdadeiramente representativos.

Como o propósito deste estudo foi o de conhecer e analisar os fatores relacionados ao consumo de óleo diesel realizou-se uma pesquisa de caráter descritivo. "As pesquisas deste tipo têm como objetivo primordial a descrição das características de determinada população ou fenômeno ou estabelecimento de relações entre variáveis" (GIL, 1995, p. 45). Buscou-se, portanto, apresentar de forma descritiva as características da população residente na cidade de Faxinal do Soturno sobre seus gostos e preferências no consumo do óleo diesel.

\section{Fonte dos dados}

Os dados apresentados são de natureza primária, obtidos através de um levantamento, com entrevista direta às pessoas cujo comportamento se deseja conhecer. Segundo Gil (1995), os levantamentos podem ser de dois tipos: recolhimento de informações sobre todo o universo pesquisado, tendo-se um censo; ou seleção, mediante procedimentos estatísticos, de uma amostra significativa de todo o universo, denominado levantamento por amostragem. Neste trabalho, fez-se uso do levantamento por amostragem, devido à impossibilidade de se atingir toda a população para a coleta dos dados.

A coleta dos dados foi realizada mediante entrevistas com aplicação de formulários estruturados junto aos consumidores de óleo diesel em Postos de combustíveis distribuídos pelos bairros da cidade. Segundo Gil (1995), a entrevista estruturada tem como característica a relação fixa de perguntas pré-formuladas, que permite a padronização das respostas para um número grande de entrevistados e é adequado à realização dos levantamentos e análise estatística dos resultados obtidos. 


\section{REGEX广UFSM}

MARZARI et all , v(11), no 11, p. 2377-2388, JUN, 2013.

Rev. Elet. em Gestão, Educação e Tecnologia Ambiental (e-ISSN: 2236-1170)

\section{Amostragem}

Segundo Schneider (2004), a amostragem é uma ferramenta estatística utilizada quando a população - conjunto total dos elementos que se busca analisar - é composta por um número muito grande de elementos, o que impossibilita o acesso a toda a população para a coleta dos dados. Assim, uma amostra é selecionada, com número e característica significativos de elementos dentro da população, para que os resultados da amostra sejam suficientemente informativos para se inferir conclusões a cerca de parâmetros de toda a população em análise.

A amostra total para população finita e conhecida foi calculada conforme Schneider (2004):

$$
n=\frac{\left(t_{\delta} \frac{\alpha}{2}\right)^{2} \times s^{2} \times N}{e_{0}^{2}(N-1)+\left(t_{\delta}, \frac{\alpha}{2}\right)^{2} \times s^{2}}
$$

Onde:

$\mathrm{n}=$ tamanho mínimo da amostra calculada;

$t_{\delta \frac{\alpha}{2}},=$ valor de $t_{\text {tab }}$ admitindo $\alpha=5 \%$;

$\mathrm{s}^{2}=$ variância obtida através da amostra piloto;

$\mathrm{N}=$ tamanho da população;

$\mathrm{e}_{0}^{2}=$ quadrado do erro amostral, obtido com os dados da amostra piloto.

Segundo dados do Censo de 2007 realizado pelo IBGE, a população de Faxinal do Soturno totalizava 6.343 habitantes. Anteriormente à definição da amostra para a coleta efetiva dos dados, foi realizada uma pesquisa piloto compreendendo um conjunto de 10 consumidores a fim de obter informações sobre a população em análise para determinar o tamanho mínimo da amostra necessária para a pesquisa, visando-se um nível de confiança de 95\%. A pesquisa piloto apresentou um desvio-padrão no consumo de óleo diesel de 350 , desvio padrão de 16,5 , e um erro amostral de $5 \%$, obtidos através da quantidade revelada em litros de óleo diesel comprado por consumidor. A amostra resultou num total de 45,09 pessoas, ou seja, 45.

Foi utilizada a técnica de amostragem estratificada, onde é dividida a população total a ser inferida em grupos menores, geralmente chamados de estratos, que, segundo Barbetta (2008, p. 48) "são grupos internamente mais homogêneos que a população toda, com respeito às principais variáveis em estudo". A amostra foi estratificada em dois grupos, homens e mulheres, com o objetivo de atingir maior homogeneidade das características dos indivíduos em cada estrato e obter informações passíveis de comparação entre sexos diferentes dos consumidores de óleo diesel. Os dados do censo de 2007 (IBGE, 2007) mostram que do total de 6343 habitantes de Faxinal do Soturno, 40,9\% são homens e $59,1 \%$ são mulheres. Desta forma, a amostra total de 45 elementos ficou dividida em 33 homens e 12 mulheres. 
Rev. Elet. em Gestão, Educação e Tecnologia Ambiental (e-ISSN: 2236-1170)

\section{Formulários e a coleta dos dados}

Os formulários aplicados nas entrevistas eram compostos por questões específicas que pretendiam alcançar as variáveis chaves para a elaboração deste trabalho. São elas: sexo; idade; escolaridade; renda; frequência semanal do consumo de óleo diesel; média, quantidade de veículos por família, conscientização do meio ambiente, marca e modelo do veículo.

Os formulários aplicados permitiram a obtenção de respostas padronizadas, já que se trata de questionários estruturados, com perguntas fechadas. Isso possibilitou a análise estatística dos mesmos, que foram analisados quantitativa e qualitativamente, conforme se apresenta na seção de resultados, a seguir.

\section{RESULTADOS E DISCUSSÕES}

\section{Descrição socioeconômica}

A amostra total coletada foi de 45 pessoas, sendo 33 pessoas do sexo masculino e 12 pessoas do sexo feminino. Os entrevistados apresentam uma média de 45,26 anos de idade (desvio padrão de 11,50 anos), sendo 42,66 anos de idade em média para mulheres e 46,21 anos para homens. A distribuição por faixa etária está ilustrada na Figura 1.

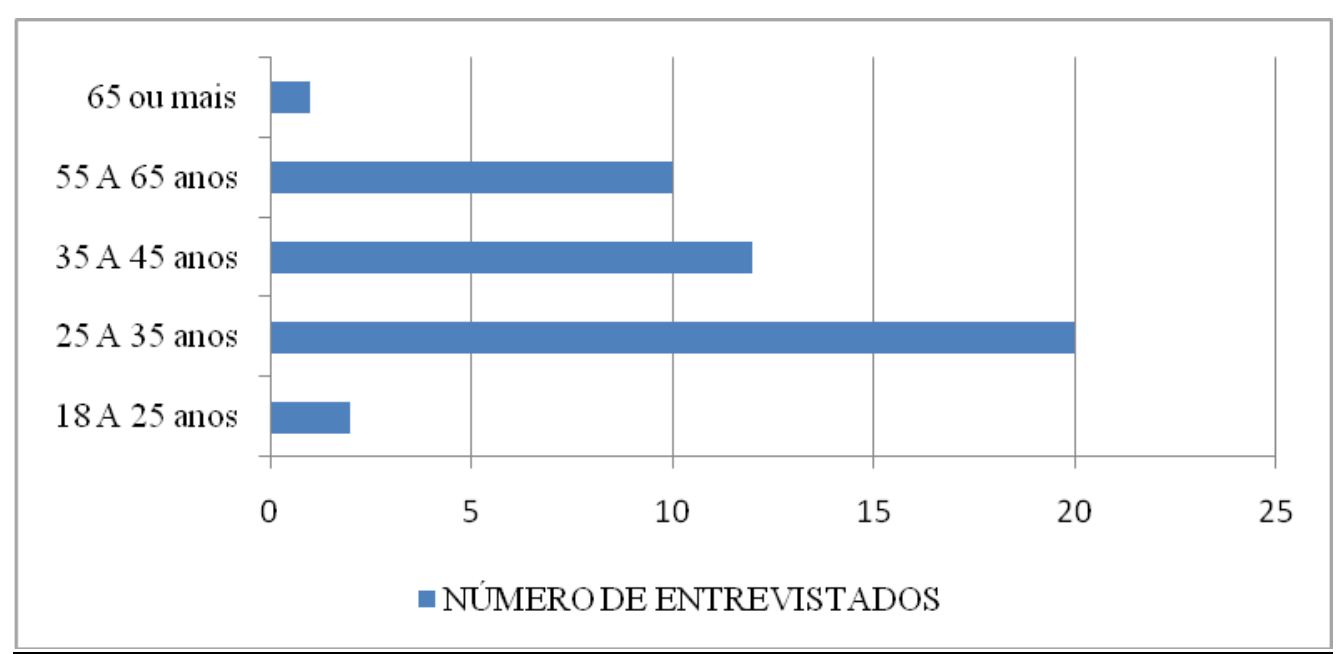

Figura 1. Distribuição da amostra por faixa etária dos entrevistados Fonte: Elaborado a partir dos dados da pesquisa.

A faixa etária de 25 a 35 anos de idade mostrou um número mais elevado de entrevistados (20) em relação às demais categorias. Isso se deve, em parte, ao grande número de 


\section{REGEX广AFSM}

Rev. Elet. em Gestão, Educação e Tecnologia Ambiental (e-ISSN: 2236-1170)

jovens que estão trabalhando na cidade de Faxinal do Soturno, atraídos por oportunidades de trabalho, e aos jovens que investem em veículos para uso no trabalho (Figura 1).

Em média, os entrevistados apresentaram 11,6 anos de estudo, o que corresponderia ao ensino médio completo (desvio padrão de 4,9 anos). A maior parcela da amostra distribui-se entre ensino superior completo e ensino fundamental completo (Figura 2).

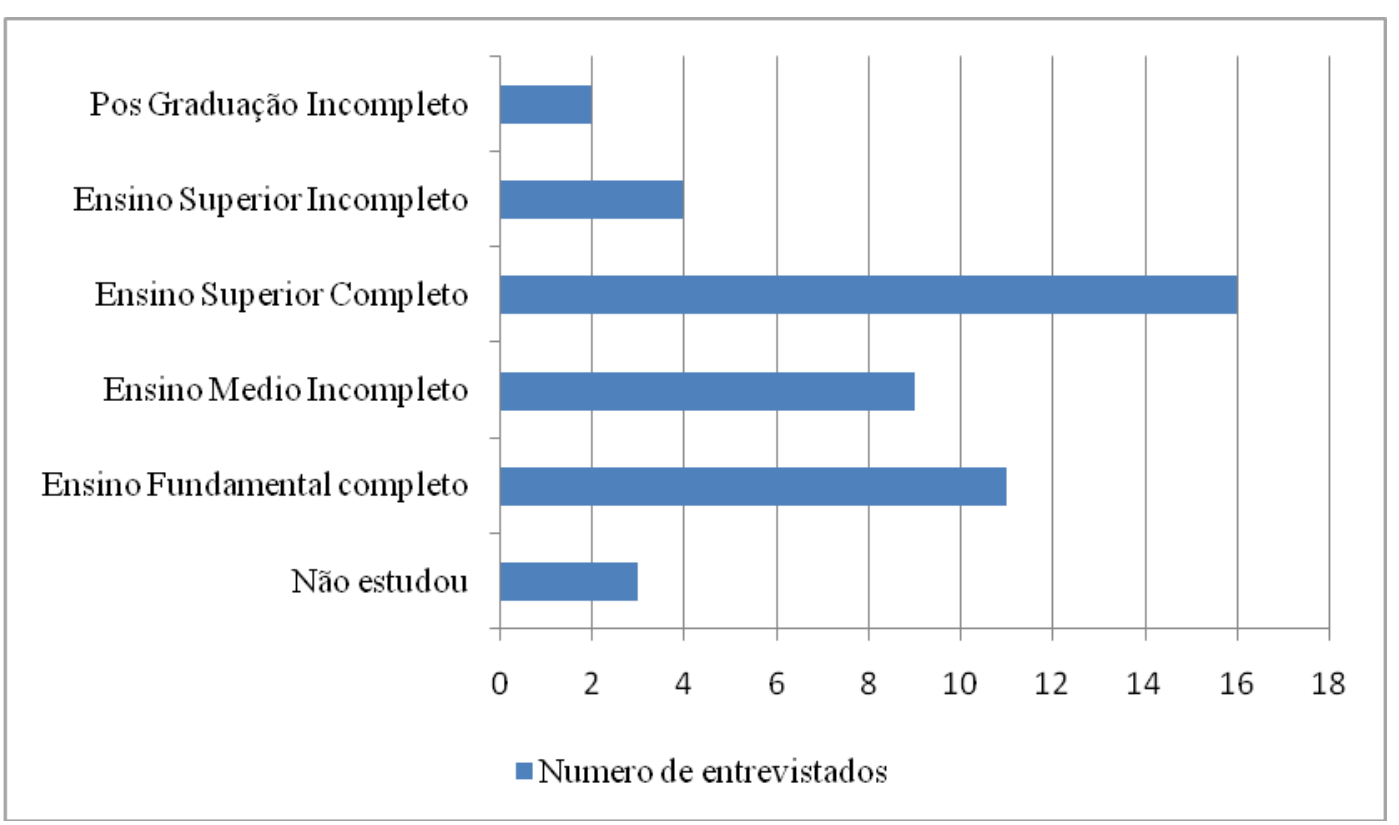

Figura 2. Distribuição da amostra por grau de escolaridade dos entrevistados Fonte: Elaborado a partir dos dados da pesquisa.

A renda média dos entrevistados foi de $\mathrm{R} \$$ 4.331,11 mensais (desvio padrão de $\mathrm{R} \$$ $4.193,00)$. Este valor apresentou-se consideravelmente igual entre homens e mulheres, o que mostra que as mulheres estão conquistando os mesmos níveis salariais que os homens. A renda dos 18 (40\%) entrevistados concentrou-se em primeiro lugar entre um e três salários mínimos ${ }^{1}$. Em segundo lugar, 14 entrevistados (31,1\% da amostra) apresentaram níveis de renda de quatro a seis salários mínimos. A análise de correlação entre a idade em anos e escolaridade em anos indicou um índice de $-0,744$, significativo a $1 \%$. Este resultado revela que quanto maior a idade, menor a escolaridade.

Os tipos de óleos mais conhecidos e usados pelos consumidores são S1800, S500 e o S50. O S1800 é também chamado de óleo diesel comum, pois não recebe nenhum aditivo. Este óleo possui $1800 \mathrm{mg}$ de enxofre e pode ser usado em qualquer veículo a diesel. O S500, por sua vez, é chamado de óleo diesel metropolitano e não recebe nenhum aditivo. Possui $500 \mathrm{mg}$ de enxofre e é usado em qualquer tipo de veículo. Por fim, o S50 é o óleo diesel com menor teor de enxofre no mercado, recomendado para veículos com motor 2012, devido às suas características, o mesmo

\footnotetext{
${ }^{1} \mathrm{O}$ salário mínimo vigente durante a realização deste trabalho foi de $\mathrm{R} \$ 622,00$. http://cascavel.ufsm.br/revistas/ojs-2.2.2/index.php/reget
} 
Rev. Elet. em Gestão, Educação e Tecnologia Ambiental (e-ISSN: 2236-1170)

melhora a partida a frio. Este óleo diminui a formação de depósitos no motor e reduz em até $90 \%$ a emissão de enxofre e a fumaça branca.

Observa-se na Figura 3 as vendas de diesel S1800, S500 e S50. Os dados revelam que o consumo do óleo S1800 lidera as vendas representando 65,9\% do total de diesel. O óleo S500 representa $27,7 \%$ do total, enquanto que o 550 , representa somente $5,30 \%$ do total.

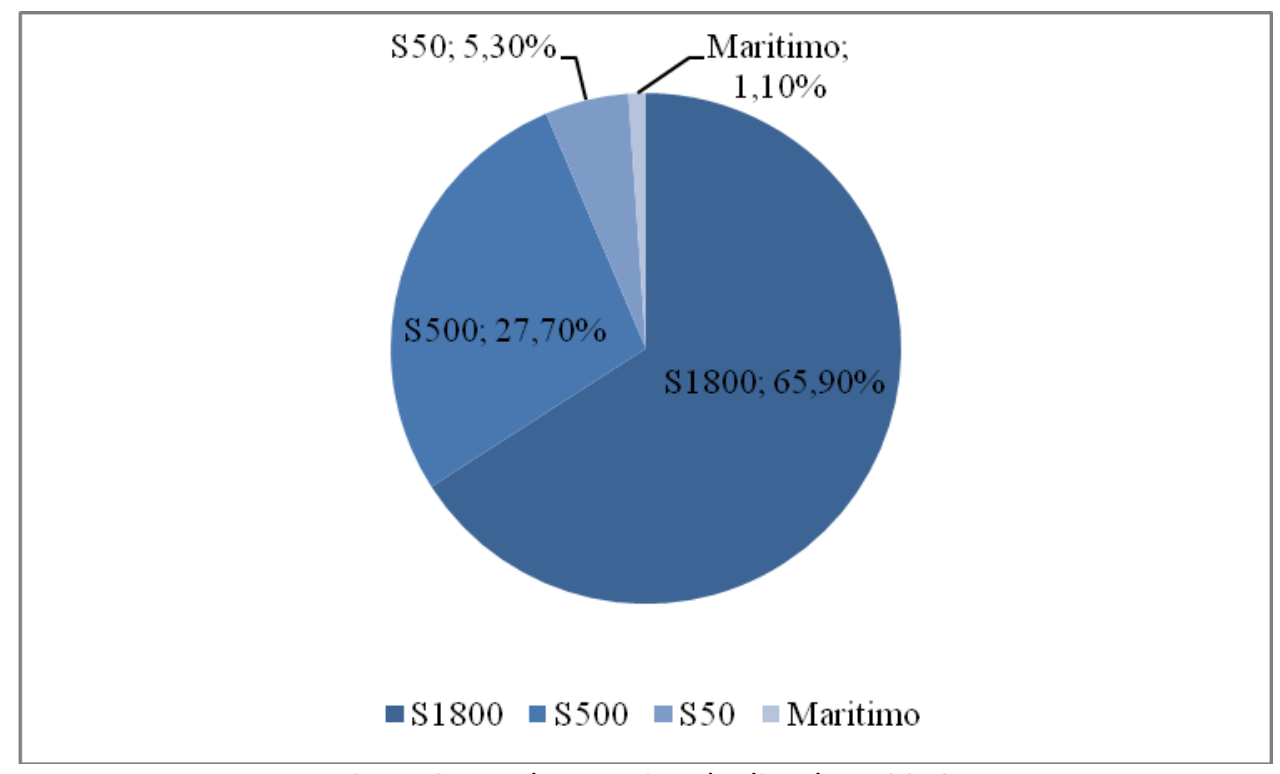

Figura 3. Vendas por tipo de diesel em 2010 Fonte: ANP, 2012.

Dentre o total de entrevistados, 19 (42,22\%) pessoas tem preferência pelo diesel S1800 e pelo diesel S50 e somente sete pessoas $(15,56 \%)$ preferem o diesel S500. A pesquisa revela que as pessoas estão conscientes e procuram poluir menos o meio ambiente. Tendo em vista, que os entrevistados que possuem maior conhecimento sobre as especificações de cada tipo de diesel, optam pelo S50. No entanto, as que optam por S1800 consideram o fator preço como variável mais importante. As oscilações de preço do óleo diesel na região estudada podem ser conferidas na Tabela 1.

Tabela 1. Oscilação de preços no Diesel S1800, S500 e S50 na Região da Quarta Colônia no ano de 2012

\begin{tabular}{l|c|c|c|c|c|c}
\hline \multirow{2}{*}{ Produtos } & \multicolumn{6}{c}{ Comparação de preços em diversas cidades da Quarta Colônia. } \\
\cline { 2 - 7 } & Nova Palma & $\begin{array}{c}\text { Faxinal do } \\
\text { Soturno }\end{array}$ & $\begin{array}{c}\text { Dona } \\
\text { Francisca }\end{array}$ & Agudo & $\begin{array}{c}\text { Restinga } \\
\text { Seca }\end{array}$ & Ivorá \\
\hline S1800 & 2,15 & 2,12 & 2,13 & 2,12 & 2,14 & 2,14 \\
S500 & - & 2,21 & - & - & - & - \\
S50 & - & 2,31 & - & - & - & - \\
\hline
\end{tabular}




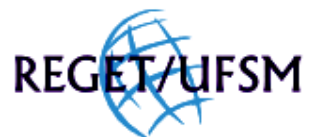

MARZARI et all , v(11), no 11, p. 2377-2388, JUN, 2013.

Rev. Elet. em Gestão, Educação e Tecnologia Ambiental (e-ISSN: 2236-1170)

Fonte: Elaborado a partir de dados secundários da Pesquisa de Preços de Postos de Combustíveis da Região da Quarta Colônia.

Conforme a Figura 4, dentre as 19 pessoas que preferem o diesel S1800, nove (20\%) delas consomem entre 50 e 100 litros mensais, oito $(17,77 \%)$ pessoas consomem entre 100 e 200 litros mensais, e duas $(4,44 \%)$ pessoas consomem entre 200 e 300 litros mensais.

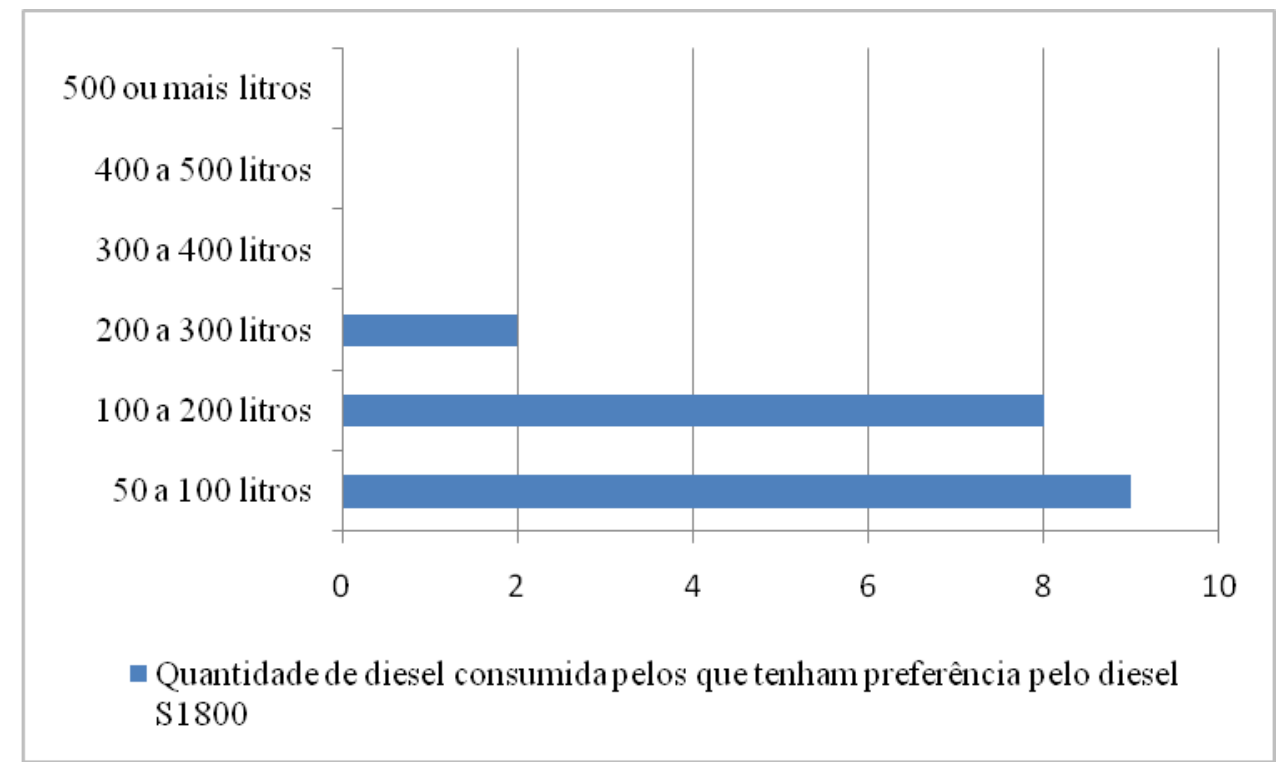

Figura 4. Quantidade consumida pelos consumidores de diesel S1800 Fonte: Elaborado a partir dos dados da pesquisa.

A Figura 5 mostra que somente quatro entrevistados $(8,88 \%)$ consomem mais de 500 litros mensais do óleo S500. Observa-se que o consumo é ainda incipiente deste tipo de óleo. Devido às recomendações das companhias de petróleo, este é um diesel que quando posto no tanque de combustível precisa ser consumido rapidamente, pois o mesmo contem gorduras vegetais que podem causar danos aos veículos caso o mesmo fique parado por períodos mais longos. Dessa forma, os consumidores que mais usam este tipo de óleo são os que mais circulam com seus veículos. 


\section{REGEXfHFS}

MARZARI et all , v(11), no 11, p. 2377-2388, JUN, 2013.

Rev. Elet. em Gestão, Educação e Tecnologia Ambiental (e-ISSN: 2236-1170)

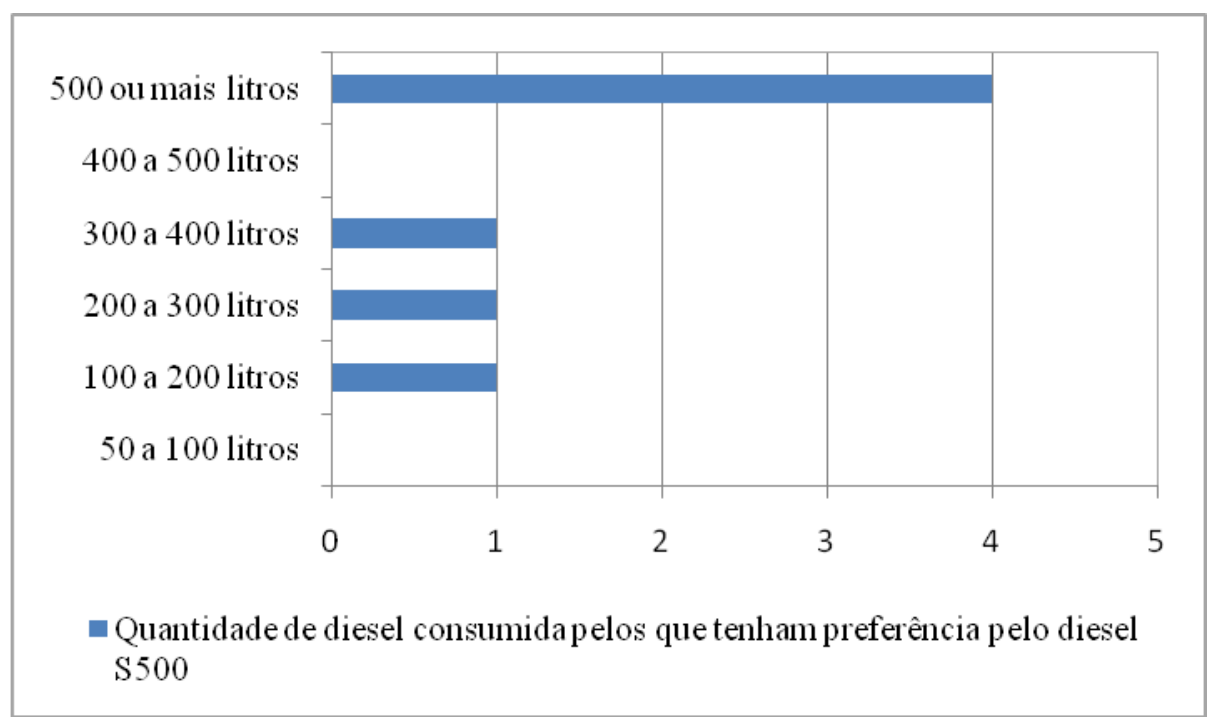

Figura 5. Quantidade consumida pelos consumidores de diesel S500

Fonte: Elaborado a partir dos dados da pesquisa.

De forma similar, o consumo de óleo S50 também é relativamente baixo. Somente seis pessoas $(13,33 \%)$ consomem mais de 500 litros mensais. Por ser um tipo de diesel novo com nova fórmula, de baixo teor de enxofre e menos poluente, este diesel é recomendado para veículos novos. Devido ao Imposto sobre Produtos Industrializados (IPI) reduzidos houve uma procura maior por veículos novos, fato que contribui para que aumentasse proporcionalmente a venda de diesel S50. Este resultado mostra que a maioria dos consumidores de S50 usam seus veículos para lazer e diversão.

Em relação à problemática da poluição ao meio-ambiente, a Ipiranga Produto de Petróleo criou o programa Segurança e Meio Ambiente que disponibiliza manuais técnicos e ferramentas práticas para o consumidor. Também neste sentido, a Petrobrás Distribuidora S/A criou programa Jogue Limpo destinado ao recebimento de embalagens de óleos lubrificantes devolvidos pelos consumidores. As estatísticas do Programa Jogue Limpo mostram que 15.000 embalagens recolhidas em diversas cidades brasileiras até janeiro de 2013.

\section{Preferência dos consumidores por óleo diesel}

Com o intuito de compreender as razões que levam consumidores a comprarem veículos a diesel, e quais as variáveis que explicam a escolha de determinado tipo de óleo, os dados revelam que a escolha pelo S1800 se dá em função do preço (100\% dos entrevistados) pelo fato deste ser o mais barato. No entanto, quando sugerido a estes consumidores para que abasteçam outro diesel com o preço até dois centavos mais caro (diferença entre os preços é de $R \$ 0,05$ ), $22,22 \%$ dos consumidores estariam dispostos a trocar de diesel (Figura 6). 
Rev. Elet. em Gestão, Educação e Tecnologia Ambiental (e-ISSN: 2236-1170)

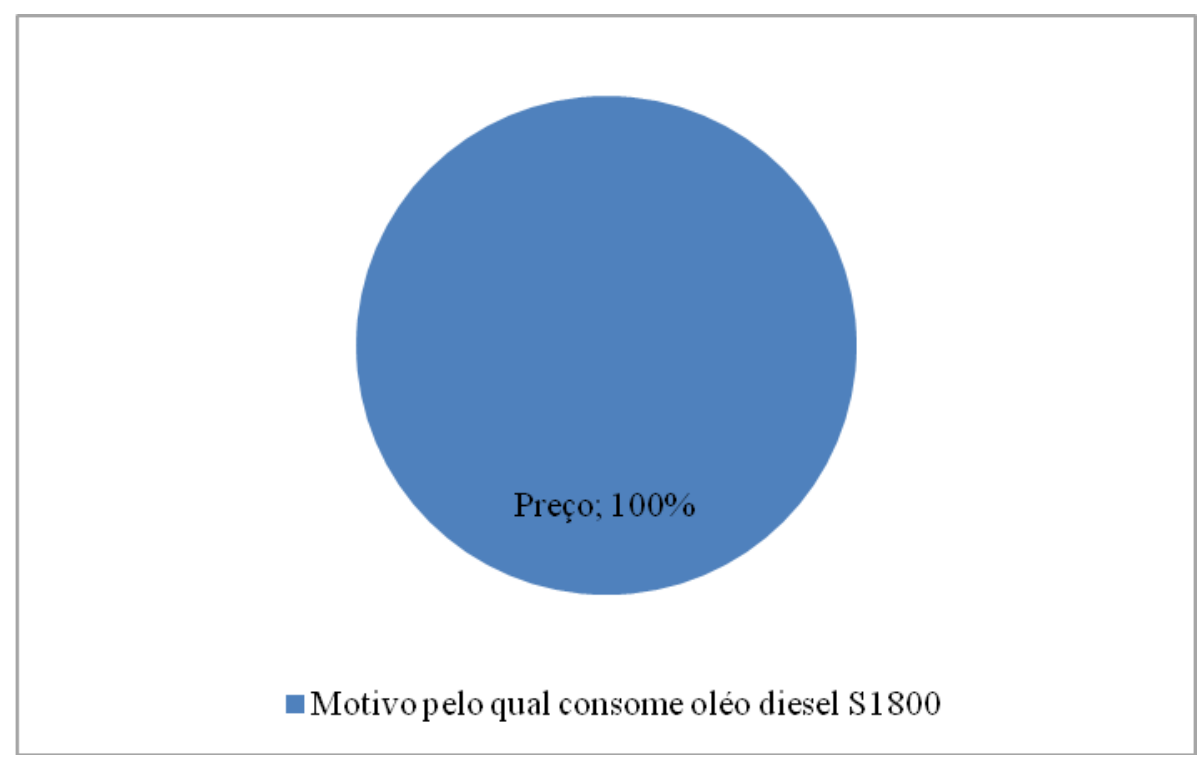

Figura 6. Preferência pelo qual consomem óleo diesel S1800 Fonte: Elaborado a partir dos dados da pesquisa.

A Figura 7 mostra os motivos pela escolha do óleo S500. Os resultados indicam que, dentre os sete entrevistados que utilizam este tipo de óleo, para 13,34\% dos entrevistados, o melhor desempenho do veículo em função do rendimento é o principal motivo. Já, 9,53\% dos consumidores trocariam de diesel caso a diferença de preço baixasse para até $R \$ 0,03$ (três centavos) por litro. Em relação à preferência por veículo, dentre os consumidores que abastecem o óleo S500, os dados mostram que 9,53\% possuem veículos da marca Toyota, modelo Hillux, em função do status (satisfação pessoal).

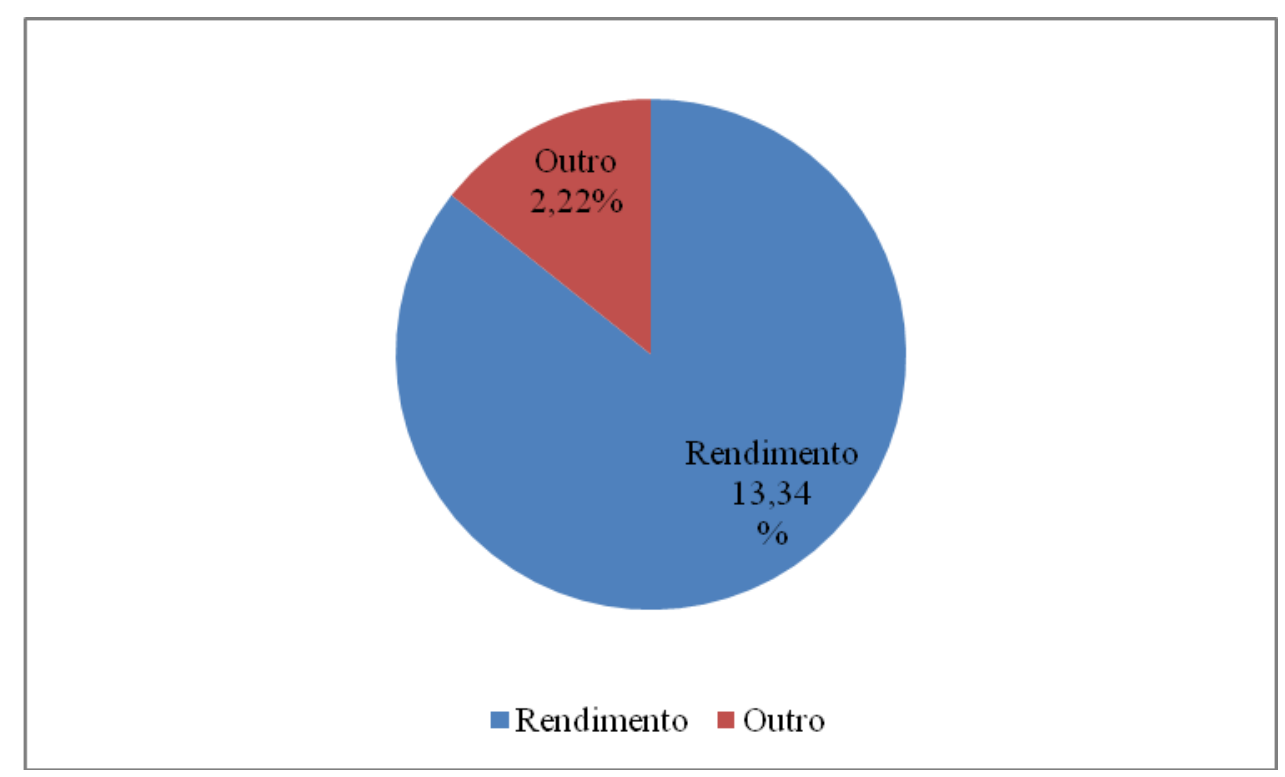

Figura 7. Preferência pelo qual consomem óleo diesel S500

Fonte: Elaborado a partir dos dados da pesquisa.

http://cascavel.ufsm.br/revistas/ojs-2.2.2/index.php/reget 
REGEXfTFSM

MARZARI et all , v(11), no 11, p. 2377-2388, JUN, 2013.

Rev. Elet. em Gestão, Educação e Tecnologia Ambiental (e-ISSN: 2236-1170)

Por fim, a Figura 8 mostra as preferências dos consumidores pelo óleo diesel S50. Dentre os motivos destacam-se o melhor rendimento do veículo $(15,56 \%)$ e pelo menor teor de enxofre (13,33\%). Já, 42,22\% dos consumidores abastecem este diesel porque são recomendações de fábrica.

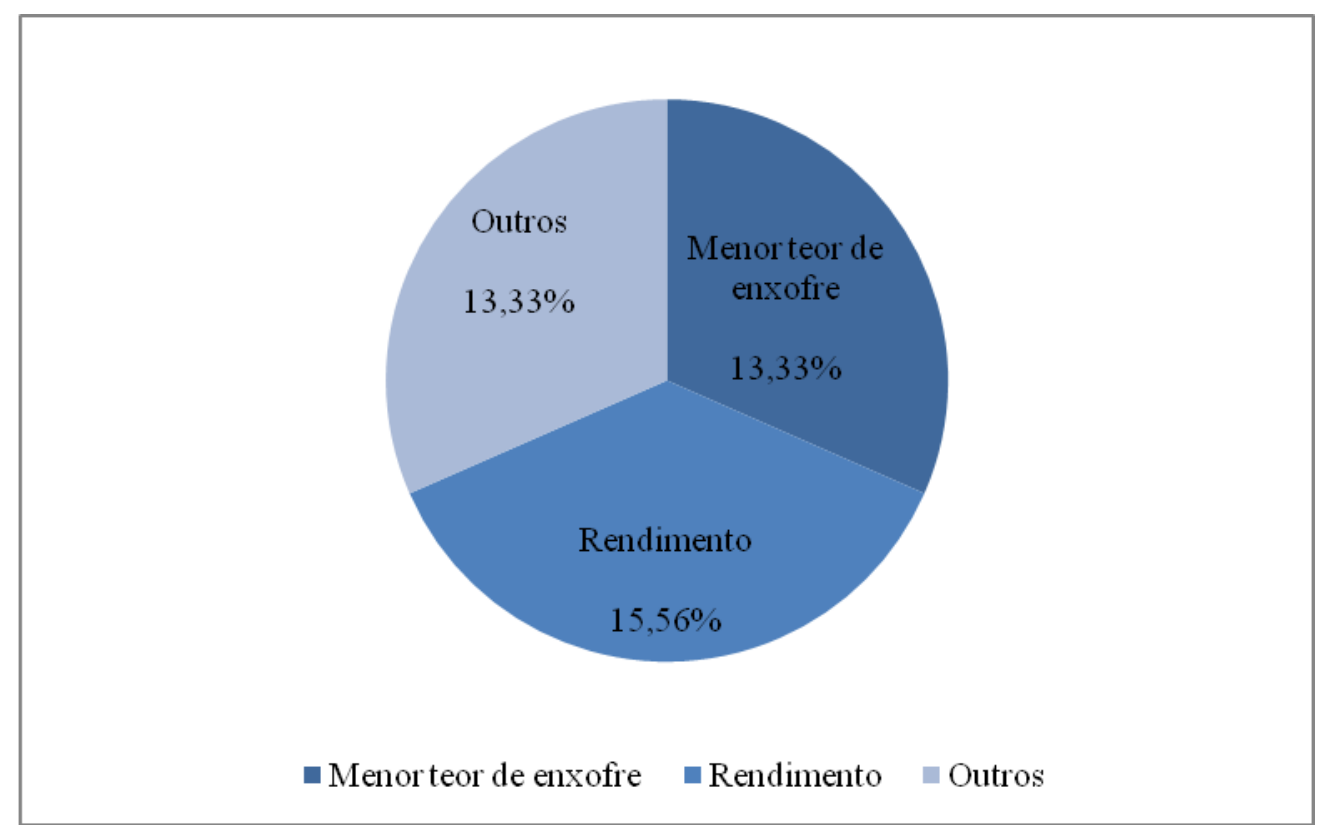

Figura 8. Motivo pelo qual consomem óleo diesel S50.

Fonte: Elaborado a partir dos dados da pesquisa.

Em relação à preferência por tipo de veículo, 5,55\% dos consumidores de S50 possuem veículo modelo Toyota Hillux devido ao conforto.

\section{CONCLUSÕES}

Os consumidores preferem o óleo diesel S1800 (42,22\%) pelo fato deste ser o de menor preço. No entanto, estes consumidores não possuem conhecimento sobre potenciais problemas causados ao meio-ambiente. Este grupo de consumidores consome 120 litros mensais e recebem uma renda média de $\mathrm{R} \$ 1.900,00$. De forma geral, estes consumidores possuem veículos mais antigos.

Os consumidores que preferem o óleo diesel S50 (42,22\%) o escolhem em função de este ser menos poluente e possuir uma fórmula com teor de enxofre considerado baixo. Estes consumidores estão mais preocupados com o meio ambiente. A compra de veículos novos fez com que aumentasse a demanda por este óleo, tendo-se em vista ser este o óleo recomendado para os motores com ano de fabricação 2012. Estes consumidores consomem um montante maior de óleo (mais de 500 litros mensais) e possuem uma renda média de $\mathrm{R} \$ 4.000,00$.

A preferência pelo óleo $\mathrm{S} 500$, por sua vez, é feita por um pequeno grupo de consumidores. Este óleo possui mais misturas de produtos gordurosos e o mesmo é escolhido em 


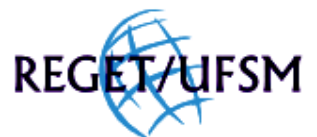

MARZARI et all , v(11), no 11, p. 2377-2388, JUN, 2013.

Rev. Elet. em Gestão, Educação e Tecnologia Ambiental (e-ISSN: 2236-1170)

função de proporcionar um bom rendimento. No entanto, veículos utilizados de forma esporádica, tendem a ter problemas de motor devido ao acúmulo excessivo de gorduras. Em comparação aos demais grupos de consumidores, este grupo é o que mais consome diesel (900 litros mensais) e possui renda mais alta $(\mathrm{R} \$ 8.000,00)$.

As limitações encontradas por esta pesquisa deteve-se, principalmente, na coleta dos dados, que, por serem de natureza primária, dependeram da colaboração do público com as entrevistas.

Sugere-se que estudos mais aprofundados sejam realizados sobre as características dos consumidores de diesel e sobre as exigências do mercado. Estudos desta natureza são de grande importância para o direcionamento das estratégias das companhias de distribuição de diesel.

\section{REFERÊNCIAS BIBLIOGRÁFICAS}

AGÊNCIA NACIONAL DO PETRÓLEO, GÁS NATURAL E COMBUSTÍVEL (ANP - 2012) - Matriz de Consumo veicular em 2009 e 2010. Disponível em: <http://www.anp.gov.br>. Acesso em: 12 dez. 2012.

BARBETTA, P. A. Estatística Aplicada às Ciências Sociais. 7. ed. Florianópolis: Editora da UFSC, 2008.

CONFEDERAÇÃO NACIONAL DO TRANSPORTE. Os impactos da má qualidade do diesel brasileiro. Brasília: CNT, 2012.

FEDERAÇÃO NACIONAL DO COMERCIO DE COMBUSTÍVEIS E LUBRIFICANTES (FECOMBUSTÍVEIS - 2012). Relatórios

Anuais. Disponível em: <http://www.fecombustiveis.org.br>. Acesso em: 19 dez. 2012

GIL, A. C. Métodos e Técnicas de Pesquisa Social. 4. ed. São Paulo: Editora Atlas, 1995.

IBGE. Instituto Brasileiro de Geografia e Estatística. Censo Demográfico de 2007. Disponível em: <http://www.ibge.gov.br/cidadesat/painel/painel.php?codmun=430800\#topo>. Acesso em: 05 dez. 2012.

SCHNEIDER, L. Estimativa dos Gastos dos Alunos da UFSM (2002): Aplicação da Amostragem Estratificada Proporcional. 2004. Monografia (Especialização em Estatística e Modelagem Quantitativa) - Universidade Federal de Santa Maria, Santa Maria, 2004.

SILVA, R. A. M. S. Porque estudar o comportamento do consumidor de carnes? Informativo da Cadeia da Carne Bovina do Pantanal Mato-Grossense, n. 004, p. 1-4, 2009.

SINDICATO NACIONAL DAS EMPRESAS DE DIESEL E LUBRIFICANTES (SINDICOM). Vendas de combustíveis pelas associadas de Sindicom e Mercado da ANP. Disponível em: www.sindicom.com.br Acesso em: 15 dez. 2012.

REFAP. Refinaria Alberto Pasqualini. Disponível em: <http://www.petrobras.com.br/pt/quem-somos/principaisoperacoes/\#/refinarias/alberto-pasqualini> Acesso em: 15 dez. 2012. 